INVESTIGACIONES

\title{
EL INDIGENA “LATINOAMERICANO” EN LA ENSENAANZA: REPRESENTACION DE LA COMUNIDAD INDIGENA EN MANUALES ESCOLARES EUROPEOS Y LATINOAMERICANOS
}

\author{
The 'Latin American' Native in the Teaching Process: \\ The Representation of the Native Community in European \\ and Latin American SchOOL BoOKS
}
O indígena 'latinoamericano' no ensino: Representação da comunidade indígena em manuais escolares europeus e latino americanos

\begin{abstract}
Robert Aman*
*Candidato a Doctorado, Universidad de Linköping. Magíster en Historia, Universidad de Karlstad. Contacto: Departamento de Ciencias de Comportamiento y Aprendizaje (IBL), Universidad de Linköping, SE-58183, Linköping, Suecia. Correo: Robert.aman@liu.se
\end{abstract}

\begin{abstract}
RESUMEN
El presente escrito compara la representación de los indígenas y su cultura en libros escolares en Suecia con sus equivalentes en Colombia. El objetivo es indagar si existen diferencias y similitudes en la reproducción de la comunidad indígena en ambos países. El estudio concluye que aunque los libros escolares de Colombia profundizan en el rendimiento de los hechos, en cuanto a la extensión textual para la descripción y explicación de los hechos, en ambos países es consistente la tendencia a representar a los indígenas como diferentes y considerarlos como inferiores. Específicamente en la forma de explicar su forma de vivir y sus conocimientos, donde encontramos explicaciones de lo que tenían y no tenían, lo que conocían y no conocían: todo hecho desde un punto de vista euro céntrico.
\end{abstract}

Palabras clave: Libros escolares, indígenas, eurocentrismo, América Latina, Suecia, Colombia.

\begin{abstract}
In this article we compare how the native population of Latin America and their culture is represented in History schoolbooks both in Sweden and in Colombia. The aim was to find out if there are differences and similarities in the reproduction of the native community in both countries. The study shows that Colombian schoolbooks give information more thoroughly, describing and explaining the facts, however, both countries consistently show the trend to represent the natives as being different and inferior, especially when describing their way of living and their knowledge. We find explanations about what they owned and what they did not own, what they knew and did not know, all focused from a Eurocentric perspective.
\end{abstract}

Key words: Schoolbooks, native people, eurocentric, Latin America, Sweden, Colombia.

\section{RESUMO}

Este estudo compara a representação dos povos indígenas e sua cultura nos livros escolares na Suécia, com os seus homólogos na Colômbia. O objetivo é investigar se há diferenças e semelhanças na reprodução da comunidade indígena nos dois países. O estudo conclui que os livros escolares da Colômbia dão informação mais detalhada, descrevendo e explicando os fatos, no entanto, os dois países mostram, de maneira consistente, a tendência a representar os povos indígenas como sendo diferentes e inferiores, especificamente na forma de explicar o seu modo de vida e seu conhecimento. Encontramos explicações sobre o que eles possuíam e o que não possuíam, sobre o que sabiam e o que não sabiam: tudo enfocado a partir de uma perspectiva eurocêntrica.

Palavras-chave: Livros escolares, indígenas, eurocentrismo, América Latina, Suécia, Colômbia. 


\section{INTRODUCCION}

En este artículo vamos a estudiar la representación de los indígenas y su cultura en los libros escolares del bachillerato en Suecia con sus equivalentes en Colombia, para indagar si existe concordancia o diferencia en la transmisión del mismo acontecimiento histórico en los libros escolares de un país latinoamericano y un país europeo.

La escasa presencia de la historia latinoamericana en los textos de historia estudiados en el bachillerato en Suecia durante los años 1990 dieron origen a mi interés por el tema. La historia de este continente sólo fue un tema de las clases en relación con el Renacimiento. Consecuentemente, aspectos relacionados con las ideas renacentistas, las invenciones desarrolladas durante el período y su aplicación como factores decisivos para la aventura de Colón fueron el tema central de los textos. Poca, o relativamente escasa, era la descripción histórica sobre el encuentro y choque entre las dos culturas y civilizaciones que se llevó a cabo.

Durante mis estudios de historia en la universidad, la historia de la región fue representada $^{1}$ de una manera completamente diferente y se construyó otra imagen de la situación. Por ejemplo, de que la cantidad de habitantes indígenas ascendía a 90 millones antes de la llegada de los españoles, mientras la población fue reducida a 3,5 millones solamente en 150 años, a causa de enfermedades, pillaje y esclavitud. ${ }^{2}$

En su libro Galeano cita al cronista oficial Gonzalo Fernández de Oviedo cuando éste, en el siglo XVI, anotó: "Muchos dellos [los indígenas], por su pasatiempo, se mataron con ponzoña por no trabajar, y otros se ahorcaron por sus manos propias". ${ }^{3}$ Esto para escaparse de las crueldades que significaba la esclavitud.

Ya en el año 1985 advirtió el Comité Latinoamericano en Suecia que la historia del continente había sido distorsionada, seguía siéndolo y que estaba interpretada desde una perspectiva europea y construida por prejuicios. ${ }^{4}$

\section{LA INFLUENCIA DEL “OTRO” EN LO QUE TRANSMITEN LOS LIBROS ESCOLARES}

El plan de estudio para la asignatura de historia en Suecia advierte que es necesario que el alumno tenga conocimientos sobre la historia global y que a su vez pueda hacer comparaciones entre fenómenos actuales y sus orígenes históricos. Además, saber cómo diferentes puntos de vista históricos pueden afectar la imagen de los sucesos. Tenemos

1 Representación significa representar el mundo de manera significativa a otras personas usando el lenguaje. Es decir, la producción de sentido a través del lenguaje, para exponerlo brevemente. "Describir" podría ser una palabra usada en este sentido, pero existe una diferencia entre las dos porque "describir" tiene el significado de describir lo que se ve llevando los errores y faltas que vienen con este método de contar, mientras que "representar" es pensado como que reposa en el objeto o la persona que refleja el verdadero sentido como él existe en el mundo. Es un espejo que representa lo sucedido en lugar de solamente describirlo y esto es el papel de los libros escolares (Hall, 2002: 3).

2 Galeano, 2003.

3 Galeano, 2003: 31.

4 Charquero, 1985. 
que darnos cuenta de que la transmisión de la historia es diferente en la sociedad sueca en comparación con la rusa, mientras la rusa tiene otra estructura que la sociedad colombiana. Las diferencias están relacionadas tanto con tradiciones histórico-culturales como con la estructura social. Entonces, ¿podemos suponer que la historia de América Latina está representada de una manera completamente diferente y más profunda en uno de sus propios países?

Para contestar esta pregunta tenemos que fijarnos en la compleja construcción de la identidad latinoamericana, debido a que la identidad de los latinoamericanos ha sido construida por otros, porque antes de la llegada de los españoles a América Latina no existía como tal. En otras palabras, podríamos entender que el problema de identidad que tiene el continente latinoamericano y su población es un producto de la colonización. Lo plantea Simón Bolívar ya en el año 1819 ante el Congreso de Angostura:

Es imposible asignar con propiedad a qué familia humana pertenecemos. La mayor parte indígena se ha aniquilado, el europeo se ha mezclado con el americano y con el africano y éste se ha mezclado con el indio y el europeo. Nacidos del seno de una misma madre, nuestros padres diferentes en origen y en sangre son extranjeros y difieren visiblemente en la epidermis (Díaz Geniz, 2004: 43 s.)

Por lo tanto, la construcción de la identidad es un proceso complicado por la diversidad dentro del continente, porque no hay una América Latina sino muchas (Díaz Geniz, 2004). Ello provoca problemas porque los latinoamericanos quieren siempre ser como ellos, reconociendo en ellos al otro, nunca como sí mismos (Galeano, 1992). Con el "otro" se refiere a ser de otra raza o nacionalidad porque "ser indio, o ser descendiente de indígenas o ser negro o tener la piel oscura, implica, para la generalidad de los países latinoamericanos, ser menos" (Díaz Geniz, 2004: 20).

Los latinoamericanos han internacionalizado en su relato acerca de sí mismos la figura del colonizador y se quieren identificar desde el pasado hacia el futuro con el europeo o eventualmente el norteamericano. Según Díaz, los latinoamericanos han negado sistemáticamente al "otro" que se construye, el componente negro e indígena para ser parte de la hegemonía de los que han influido en su identidad. Lo admirable es no ser latinoamericano, sino blanco, europeo, occidental o norteamericano. (Díaz Geniz, 2004). Entonces ¿quién quiere ser colombiano, latinoamericano, etc.? Para entender el problema de querer ser como los "otros" tenemos que mirar en la cultura, y definir una cultura colombiana o latinoamericana es complicado, por no decir imposible, debido a la ya mencionada diversidad. Aquí podemos volver a lo que decía Bolívar sobre el caso:

Más nosotros que apenas conservamos vestigios de lo que en otro tiempo fue, y que por otra parte no somos indios ni europeos, sino una especie media entre los legítimos propietarios del país y los usurpadores españoles: en suma siendo nosotros americanos por nacimiento y nuestros derechos los de Europa (Díaz Geniz, 2004: 46).

Gran parte del problema son los libros escolares, porque son esenciales en la construcción de la identidad y su manera de representar a los propios habitantes con las características que les asignan. La representación de la historia de América Latina es 
hecha desde un punto de vista europeo, porque algo "se da" en Europa para expandirse al resto del mundo y fueron los europeos quienes "descubrieron" América. Enrique Dussel señala que Europa se autoafirma como el centro de la historia mundial y sus hechos se imponen hacia otras partes (Dussel, 1992).

Aníbal Quijano define eurocentrismo como una perspectiva de conocimiento cuya elaboración comenzó en Europa antes de mediados del siglo XVII, asociada a la secularización burguesa del pensamiento europeo y a las necesidades y a la experiencia del patrón mundial de poder capitalista, colonial, eurocentrado, establecido a partir de Europa (Quijano, 1993: 211).

Este eurocentrismo lo vemos en la enseñanza de la historia mundial donde América Latina no suele ser parte de la historia antes de 1492, como si este año fuera el nacimiento del continente y no hubiera pasado nada antes de la llegada de los españoles. Tampoco como si la población del continente no tuviera su propia historia. Lo mismo vemos en la idea de que Colón "descubrió" un "nuevo continente" como si fuera una hazaña científica, cuando en realidad encontró algo que siempre estuvo ahí (Castaño, 2006).

Europa concentró bajo su hegemonía el control de la cultura, la subjetividad y, sobre todo, del conocimiento. Es decir, la producción del conocimiento y las perspectivas de ello. En fin, los europeos generaron una nueva perspectiva temporal de la historia de los pueblos colonizados y sus propios pasados y culturas, "en el pasado de una trayectoria histórica cuya culminación era Europa" (Quijano, 1993; Mignolo, 1995).

Es en estas condiciones que los latinoamericanos tienen que formar su identidad y las características que con ella vienen. Ahora, al tener esto en cuenta, surge nuevamente la pregunta: ¿Cuáles son las diferencias entre los libros escolares de historia suecos y los colombianos de ciencias sociales?

\section{METODO}

Discutimos en la parte anterior que nadie quiere pertenecer a una cultura indígena, y entonces tenemos la perspectiva del nosotros-ellos/otros, en la que el otro es el indígena como tampoco los autores de los libros escolares, tanto en Suecia como en Colombia, no son parte de esa cultura, sino que ellos la representan. Podemos concretar estos conceptos a la luz de las categorías de análisis textual que plantea Tzvetan Todorov, quien entiende que la forma de ver al otro se constituye en tres planos: axiológico, praxeológico y epistémico (Artieda, 2005: 488).

Los planos se vinculan entre sí al generar distintas formas de relación. Cuando el nosotros valora al otro como inferior, por lo tanto menos vital o diferente, "la diferencia degrada en desigualdad". En el primer caso estamos frente a una forma de relación desigualdad-diferencia; en el segundo, igualdad-asimilación. Todorov expone que tanto Cristóbal Colón como los conquistadores como Hernán Cortés en sus formas de relación con el otro se definen diferentes identidades e imágenes de él. Además los indígenas serán objetos vivientes o sujetos productores de objeto. Así lo explica Todorov:

Colón sólo habla de los hombres que ve porque, después de todo, ellos también forman parte del paisaje. Sus menciones de los habitantes de las islas siempre aparecen entre anotaciones sobre la naturaleza, en algún lugar entre los pájaros y los árboles (Todorov, 1987: 41). 


\begin{tabular}{|l|l|}
\hline $\begin{array}{l}\text { Plano axiológico. } \\
\text { Juicios de valorar }\end{array}$ & $\begin{array}{l}\text { El otro es mi igual. } \\
\text { El otro es mi inferior. }\end{array}$ \\
\hline $\begin{array}{l}\text { Plano praxeológico. } \\
\text { Acción de acercamiento o de alejamiento. }\end{array}$ & $\begin{array}{l}\text { Sumisión al otro. Adopto sus valores, me identifi- } \\
\text { co con él. } \\
\text { Sumisión del otro. Asimilo el otro a mí, le impon- } \\
\text { go mi propia imagen. }\end{array}$ \\
\hline Plano epistémico. & $\begin{array}{l}\text { Conozco o ignoro al otro, en una "gradación } \\
\text { infinita" entre los estados de conocimiento más o } \\
\text { menos elevados. }\end{array}$ \\
\hline
\end{tabular}

Los atributos que Colón les asigna a los indígenas contribuyen a las imágenes de hacerles sujetos y aproximarles a la naturaleza por su ausencia de leyes, religión católica y lengua española. Todorov expone a Cortés como ejemplo para ejemplificar el concepto de sujetos de productores de objetos porque esta imagen es equivalente a considerarles como fuerza de trabajo o recurso de explotación. Esto también operó como estrategia para vencerles y explotarles. De este modo dejan de ser objetos naturales, pero tampoco sujetos plenos; en todo caso están en medio camino. Se puede encontrar esta imagen en la sujeción de los indígenas a las encomiendas y las mitas. "En las imágenes reseñadas, el único ser que alcanza los atributos de sujeto es el blanco, en un modo de relación que equipara diferencia con desigualdad". De este sentido la igualdad niega la identidad del otro porque equivale a asimilación y anula las diferencias desvalorizándolas.

[Los españoles] No reconocen la existencia de lenguajes, formas políticas y de organización social, costumbres y valores, concepciones del mundo y religiones distintas de los propios. En consecuencia, únicamente pueden vincularse con los indígenas incorporándolos en forma continua, como elementos sumados a su propio universo, marcado por la escisión entre cristianos y bárbaros (Artieda, 2005: 490).

Estos son claves del discurso de Todorov de las que van a ser usadas en este estudio. Todorov plantea diferentes versiones de las relaciones entre el nosotros y el otro, "y a la vez advierte que son variaciones de un universal impuesto, la proyección de los valores del nosotros eurooccidental en el otro indígena" (Todorov, 1987: 41).

\section{LOS LIBROS ESCOLARES}

La edad de los alumnos se diferencia probablemente en los dos países. En la asignatura "Historia" se empieza con la historia del propio país para luego expandirse a la del continente y la del mundo. Por lo tanto, los alumnos suecos son mayores cuando llegan al capítulo que trata de la historia latinoamericana. Normalmente lo estudian durante la época escolar llamada el bachillerato que en Suecia es el nivel antes de poder ingresar en la universidad donde los alumnos tienen entre 15-16 años. Al investigar sobre los libros escolares destinados para el bachillerato, es posible hacerse una idea sobre el conocimiento de la materia que llegan a tener los alumnos al dejar esta 
institución de formación. También, en Suecia cada una de las disciplinas juntadas en lo que llama ciencias sociales son asignaturas propias, por lo tanto se dedican más tiempo a cuestiones históricas.

Los libros más utilizados en los bachilleratos suecos son Epos Historia y Alla tiders historia - La historia de todos los tiempos y por eso van a ser los que examinamos en este estudio. Los libros escolares colombianos son Ciencias sociales, Contextos sociales y Civilización.

\section{LOS INDIGENAS Y SU CULTURA}

La forma de representar al indígena está conectada con la forma de ver al otro. Por ejemplo, al extranjero se le ve como inferior, puesto que es diferente a nosotros porque no tiene las mismas tradiciones y cultura ni habla la misma lengua. "Se puede explicar por una incapacidad de percibir la identidad humana de los otros, es decir, de reconocerles a la vez como iguales y como diferentes" (Todorov, 1987: 84). Ya los primeros españoles que estuvieron en contacto con los indígenas se referían siempre a objetos como la arquitectura, las mercancías o las telas. Todorov compara este punto de vista con los turistas hoy en día que admiran la arquitectura, la pintura y las artesanías de los indígenas en cada continente del mundo, sin que por ello quisieran compartir la vida con ellos. Son reducidos al papel de productores de objetos, de artesanos o de juglares, cuyas hazañas se admiran, pero con una admiración que, en vez de borrar la distancia existente entre ellos y nosotros, sigue mostrándola. Esto es, que los indígenas no son considerados como sujetos, o considerado, como iguales, con el sujeto que son ellos: los españoles. En este sentido se les daba a los indígenas una posición intermedia entre sujeto y objeto, es decir, un objeto viviente a medio camino, así como se veían los propios españoles y su identidad (Todorov, 1987: 139 ss.).

\section{LA REPRESENTACION DE LOS INDIGENAS Y SU CULTURA EN LOS LIBROS ESCOLARES DE SUECIA}

En Epos Historia están representados solamente los aztecas y los incas de los indígenas del territorio que iba a ser llamado América Latina. A los indígenas y su cultura se les da un párrafo para contextualizar al lector sobre el tipo de culturas que se encontraron los europeos al llegar al continente.

En el continente había varias culturas altamente desarrolladas e imperios bien organizados. Los más importantes de ellos eran el imperio azteca en México y el imperio inca con centro en Perú. La base para ambas culturas era el gran desarrollo que daban a la agricultura. Los indígenas cultivaban maíz y en Perú también papas. Maíz y papas que no existían en el viejo mundo, daban muy ricas cosechas con poco trabajo, y no es necesario arar la tierra. Pero los indígenas no conocían el hierro y tenían solamente herramientas de piedra y madera. No usaban la rueda, y tampoco tenían animales domésticos de gran tamaño para montar ni para utilizarlos como animales de tiro. Los incas tampoco tenían ninguna escritura (Sandberg y Molin, 1996: 135). 
Alla tiders historia menciona también a los mayas al informar que bajo del Río Grande vivían tres grandes poblaciones de indígenas y que probablemente aumentaron a unos 30 millones de habitantes. Mientras en el norte sólo vivía un medio millón de indígenas, los que no habían desarrollado una cultura avanzada (Almgren y Löwgren, 2004: 81).

Al sur de Río Grande vivían tres grandes poblaciones de indígenas con culturas avanzadas: los mayas y aztecas en el sur de México y los incas en el paisaje montañoso de los Andes. Lo extraño de esta gente era que tenían sociedades bien desarrolladas donde el arte y la ciencia eran de un nivel alto. Aunque el desarrollo técnico no había avanzado lejos. Al hacer observaciones de los movimientos de los cuerpos celestes construyeron los mayas un calendario más exacto que el juliano, el cual usaron los europeos a principio del siglo XVI. Todavía no habían aprendido a producir hierro y por eso no sabían hacer armas muy efectivas. Tampoco conocían la rueda (Almgren y Löwgren, 2004: 80).

\section{LA REPRESENTACION DE LOS INDIGENAS Y SU CULTURA EN LOS LIBROS ESCOLARES DE COLOMBIA}

Los libros escolares colombianos dan más información en cada uno de ellos sobre los indígenas y su cultura. Todos incluyen información sobre los tres grandes grupos: los incas, los aztecas y los mayas y también sobre los indígenas de Colombia y sus períodos de desarrollo. En Civilización se informa que los mayas alcanzaron un alto grado cultural, que se manifiesta en sus prodigiosas obras arquitectónicas, pictóricas, literarias y científicas. También se advierte que se hicieron expertos especialistas en cosmología y astronomía, y que su calendario tiene trascendental importancia científica. Menciona que vivieron de la agricultura y explica su sistema sociopolítico.

La nobleza se consideraba de sangre diosa y entre sus integrantes se escogían los jefes para la guerra. Al estrato de los nobles seguían los comerciantes, luego los artesanos, los campesinos, y finalmente los esclavos, quienes frecuentemente eran sacrificados a los dioses (Montenegro González y Feo Basto, 1993: 136).

De los aztecas avisa Civilización que su organización económica dependía de la agricultura y que las obras más grandes de su cultura eran la arquitectura, la escultura y la pintura mural. "El Estado se regía por el sistema religioso. En el nivel más alto estaba el emperador, llamado Tlacatecuhtli, quien concentrara el poder civil, religioso y militar" (Montenegro González y Feo Basto, 1993: 144 s.). También los incas son mencionados, pero en menor extensión. El texto dice que era una sociedad jerarquizada y que se pensaba que el líder era el hijo del sol y que su poder era hereditario.

En Ciencias sociales reciben una página cada una de las culturas: mayas, incas y aztecas. Al decir que la mayoría de los mayas vivían en el campo, dedicados a la agricultura y a los oficios artesanales, señala que "entre los pueblos americanos, el maya fue el único que inventó una escritura capaz de representar fielmente el lenguaje hablado. Escribieron en las paredes de los templos y en los objetos" (Galindo Neira y Neira López, 2007: 162 ss.). Sobre los aztecas se explica de dónde venían supuestamente y su organización política y social, divididas en emperador, funcionarios estatales, nobleza, comerciantes, pueblo y 
esclavos. Además que tanto los aztecas como los mayas hacían sacrificios humanos a sus dioses. De los incas se advierte que tuvieron una ciudad principal donde comenzaron su desarrollo y desde la cual administraron su imperio: Cuzco. Informa sobre la estructura familiar de ellos y comenta que el padre tenía la responsabilidad de las artesanías y la agricultura y que además era el soporte de la economía y el único que tenía derechos políticos. Mientras el trabajo de la madre eran las tareas del hogar.

En Contextos sociales se expone que "los mayas eran expertos matemáticos y astrónomos y observaban el cielo desde elevadas pirámides escalonadas" (Tanácas y Sacive Puyana, 2004: 134). Presenta sus dioses y señala que "en su honor practicaban sacrificios humanos, danzas y juegos rituales de pelota” (Tanácas y Sacive Puyana, 2004: 134). De los aztecas dice el libro de texto cómo se organizan, qué clases sociales existían y explica su religión.

Los aztecas tenían un vasto panteón de dioses y diosas, entre los que se destacara Quetzalcoatl, o "Serpiente Emplumada", dios creador de la tierra y de las personas, el cual había enseñado la agricultura y otras artes a los aztecas, y Huitzilopochtli, el dios de la guerra, al que se ofrecían sacrificios humanos (Tanácas y Sacive Puyana, 2004: 135).

Los incas están representados de la misma manera y se explica su religión, su sistema político y su economía.

El inca era considerado el hijo del sol. Por lo tanto era una divinidad y un mediador entre el mundo de los vivos y el mundo de los dioses. En el ámbito económico, el inca organizaba a la población para obtener recursos y realizar las obras públicas. En lo político, establecía alianzas y declaraba la guerra ((Tanácas y Sacive Puyana, 2004: 215).

Sobre la cultura inca es señalado que no conocieron la escritura, pero que eran expertos en otras áreas como en la cerámica, los tejidos y la arquitectura: "construyeron monumentales palacios que se caracterizaron por su sencillez y solidez. Los materiales usados fueron básicamente piedra y adobe” (Tanácas y Sacive Puyana, 2004: 217).

\section{CONCLUSIONES}

Los libros escolares suecos dan poco espacio a los indígenas, y donde Epos Historia no menciona a los mayas. Tampoco especifica ninguno de los textos períodos de desarrollo ni permiten al lector captar diferencias comparativas de su propio desarrollo en las comunidades indígenas, les representan como si fueran iguales. De este aspecto hacen un trabajo más minucioso los libros escolares colombianos, por el hecho de que separan las comunidades indígenas para mostrar que no son una unidad y también especifican diferentes períodos.

La mayoría de los libros escolares colombianos advierten que los mayas y los aztecas hacían sacrificios humanos, sin dar una extendida explicación sobre el por qué lo hacían. Por lo tanto, dejan en manos del lector sus propias conclusiones, y pueden dar la ilusión de que eran salvajes o demasiado primitivos. Al mencionar este hecho hay que contextualizar al lector de los tiempos en los que practicaron este ritual religioso, y como no 
era una sociedad cristiana no tenían las mismas normas ni costumbres como la mayoría de los europeos o los habitantes de América Latina hoy en día.

La idea no es defender estos hechos por parte de los aztecas o de los mayas, pero un libro escolar tendría que ser objetivo, y entonces cabe preguntarse; ¿por qué representan estos hechos, pero no acciones inaceptables de otras sociedades antes de convertirse en cristianos? Hay varios ejemplos conocidos como las relaciones sexuales entre alumno y profesor en la antigua Grecia, algo que durante la época no era considerado como nada extraño. Con esta afirmación mostramos otra vez la importancia de explicar con qué punto de vista estamos estudiando a los indígenas y revelar por qué hacían así y con qué objetivos. Por ejemplo, en este caso es substancial afirmar que no todas las comunidades indígenas eran caníbales, sino la mayoría de la gente, que estaba extendida por todo el continente, no lo era, pero que había comunidades en el norte de América Latina que eran antropófagos. También que varias comunidades indígenas estaban en guerra entre sí y que los prisioneros de las batallas fueron esclavizados y de vez en cuando sacrificados a los dioses durante ceremonias religiosas.

Una similitud entre los libros escolares de ambos países es la manera de representar las materias en las que poseían grandes conocimientos: arte y ciencias, pero a la misma vez exponer las cosas que no conocían o no utilizaban. Algo que a veces está hecho sin causa y por lo tanto criticado por Todorov. El expone como ejemplo las declaraciones de que los indígenas no utilizaban animales de tiro o de gran tamaño para montar, cuando en realidad el caballo y el asno, la vaca y el camello no existían en el continente americano, entonces ¿qué animales hubieran podido utilizar los indígenas? Por lo tanto es una afirmación innecesaria, porque da la impresión al lector que los indígenas no eran suficientemente inteligentes para darse cuenta que se puede usar animales de gran tamaño para montar o usar en el trabajo de agricultura.

Al hacer una enunciación como ésta, la comparación de lo que uno tiene o carece se hace desde otro punto de vista y comparado con lo que ellos ya tienen, en este caso ellos: los europeos. Es decir, los libros escolares en ambos países tienen la perspectiva del otro, el extranjero y el europeo, mirando hacia el otro para describir lo que se ve y desde esta perspectiva llegar a conclusiones sobre de qué manera es diferente a nosotros. Al tener en cuenta a Todorov que replica su concepto de desigualdad en el que los indígenas son reducidos a lo que se le llama objetos vivientes, esto significa un camino intermedio entre sujeto y objeto.

Podríamos afirmar que en todos los libros de ambos países vemos solamente admiración por los indígenas con sus conocimientos de la arquitectura, la ciencia y el arte, por lo tanto es reducido el otro, en este caso el indígena, a un sujeto productor de objetos. Algo que es más obvio en el caso de los libros escolares de Suecia que podría ser resultado del poco espacio que recibe el continente.

Concluimos que la historia latinoamericana es representada desde un punto de vista europeo tanto en Colombia como en Suecia. Entonces muestran los resultados de esta investigación que el problema de la identidad latinoamericana sigue existiendo en los libros escolares colombianos, y que estos textos siguen negando el componente indígena o mestizaje y se identifican con "el otro", es decir, la persona que colonizó el continente y tomó control de la producción de conocimiento; el europeo. 


\section{BIBLIOGRAFIA}

Almgren, H. y Löwgren, ¿? (2004). Arne, Alla tiders historia A, Estocolmo, Gleerups. Artieda, T. (2005). "El otro más otro" "o los indígenas americanos en los textos escolares”, Jean-Louis Guereña y Gabriela Ossenbach (ed.) (2005), Manuales escolares en España, Portugal y América Latina, Madrid, UNED, pp. 485-501.

Castaño, P. (2006). “América Latina y la historia mundial”, Néstor Ganduglia y Natalia Rebetez Motta (ed.), Memorias del tercero. Foro Latinoamericano: Memoria e identidad, Montevideo, PANAL, pp. 3-24.

Charquero, G. (1985). Paraguay Trettio år av ensamhet, Estocolmo, Latinamerikakommittén.

Díaz Geniz, A. (2004). La construcción de la identidad en América Latina, Montevideo, Editorial Nordan-Comunidad.

Dussel, E. 1942 (1992). El encubrimiento del otro. La Paz, Plural.

Galeano, E. (1992). Ser como ellos y otros artículos, Madrid, Siglo XXI Editores.

Galeano, E. (2003). Las venas abiertas de América Latina, Madrid, Siglo XXI Editores.

Galindo Neira, L. E. y Neira López, A. (2002); 2007. Ciencias sociales 6, Bogotá, Santillana.

Hall, S. (¿AÑO?). El trabajo de la representación, Londres, Sage Publicationes.

Mignolo, W. (1995). The Darker Side of the Renissance: Literacy, Territoriality and Colonization. Ann Arbor, University of Michigan Press.

Montenegro González, A. y Feo Basto, J. (1995). Civilización 7, Bogotá, Norma, Quijano, A. (2000). “Colonialidad del poder, eurocentrismo y América Latina”, Edgardo Lander (ed.), Colonialidad del Saber, Eurocentrismo y Ciencias Sociales, Buenos Aires, CLACSO-UNESCO, pp. 201-246.

Sandberg, R. y Molin, K. (2003). Epos Historia A-B, Estocolmo, Almqvist \& Wiksell. Tanácas, E. y Sacive Puyana, M. (2004). Contextos sociales 7, Bogotá, Santillana.

Todorov, T. (1987). La Conquista de América Latina. El problema del otro, Buenos Aires, Siglo XXI Editores. 